\title{
Microstructure and Mechanical Properties of Magnesium Alloy Prepared by Solid -state Recycling From Two Kinds of Chips
}

\author{
Shuyan WU ${ }^{1, a^{*}}$, Zesheng $\mathrm{JI}^{2, \mathrm{~b}}$, Jun Wang ${ }^{1, \mathrm{c}}$, ,Hongbo $\mathrm{LI}^{1, \mathrm{~d}}$,Shidan $\mathrm{YUAN}^{1, \mathrm{e}}$ and \\ Ming $\mathrm{HU}^{1, \mathrm{f}}$
}

${ }^{1}$ School of Materials Science and Engineering, Jiamusi University, Jiamusi 154007,China

${ }^{2}$ School of Materials Science and Engineering, Harbin University of Science and Technology, Harbin 150040, China

awsy_hit@sina.com, 'bsy_hit@sina.com, cwsy_hit@sina.com, 'wsy_hit@sina.com, ewsy_hit@sina.com, 'wsy_hit@sina.com

Keywords: solid-state recycling; AZ31B magnesium alloy; AZ91D magnesium alloy; microstructure; mechanical property.

Abstract. The chips of AZ31B and AZ91D magnesium alloy were simultaneously recycled by solid -state process. For comparison, AZ91D and AZ31B magnesium alloy were produced by the same solid- state recycling from single AZ91 and AZ31 chip, respectively. Mechanical properties and microstructure of three recycled alloy were investigated. Recycled AZ31B and AZ91D alloy show small exquiaxed grain. In recycled alloy fabricated from two kinds of chips, AZ91 and AZ31 chips consolidate each other after being broken up during hot extruding, so the composition and microstructure of the recycled alloy are inhomogeneous. Original AZ31 part exhibits finer grain than AZ91 because more deformation concentrated in AZ31 chip during hot extruding and lead to a larger degree of dynamic recrystallization. The recycled alloy show good mechanical property, both the ultimate tensile strength and elongation to failure are intermediate at the ones of recycled AZ31B and AZ91D alloy.

\section{Introduction}

Magnesium alloys are currently the lightest alloys used as structural metals and honored as the 21 st century green structural material. Owning many advantages such as excellent mechanical properties, good machinability, good electromagnetic shielding characteristic and high dimensional stability, magnesium alloys have great application potential in aerospace, automobile and electronic device[1-4]. A large amount of magnesium alloy chips will be produced in the process of machining since magnesium alloy shows excellent machinability[5]. Recycling of chips draws more and more attentions with the increase of application for magnesium alloys [6].

A solid-state recycling has been proposed as a new method for recycling magnesium alloy chips and scraps in Japan [7,8] and Korea [9]. In solid-state recycling, magnesium alloy chips are directly recycled by hot extrusion without re-melting [10]. Solid-state recycling turns to be an efficient method because it can avoid oxidation loss in the re-melting process and save energy. Experimental evidence showed that magnesium alloys such as AZ80[11], ZK60[12], AZ91[13] and $\mathrm{Mg}-\mathrm{Al}-\mathrm{Ca}[14]$ fabricated by solid-state recycling process showed excellent mechanical properties of high strength, moderate ductility and superplastic behavior. These researches accessed the feasibility of recycling in solid-state for magnesium alloy.

AZ91 alloy is typical cast magnesium alloy and have high strength. It shows large deformation resistance and be easy to form crack on surface of products during the extrusion due to its poor deform ability. AZ31 alloy own good deformability because it contains a few amounts of secondary phase, and it is one of the most widely used wrought $\mathrm{Mg}$ alloy currently. Consequently, it is the most suitable to the recycling process in solid state. In this study, AZ31 chip and AZ91 chip were used simultaneously to fabricate magnesium alloy by solid state recycling process, and microstructure and mechanical property of the recycled material from two kinds of chips was investigated and discussed. 


\section{Experimental procedures}

The used materials in this work were AZ91D and AZ31B magnesium alloy. Chips were prepared by machining the as-received ingot in a lathe. The sizes of machined chips for AZ91 and AZ31 were $(10-16) \times(1.8-2.2) \times(0.48-0.52) \mathrm{mm}$ and $(6-10) \times(1.8-2.2) \times(0.38-0.42) \mathrm{mm}$, respectively. The chips of AZ91 and AZ31 were filled into a $40 \mathrm{~mm}$ diameter cylindrical container layer by layer alternately and were pressed into billet at room temperature. The pressure and the holding time was $350 \mathrm{MPa}$ and $60 \mathrm{~s}$, respectively. The mold with the formed billet was heated to $673 \mathrm{~K}$ and holded for $20 \mathrm{~min}$, then hot extrusion were carried out in air at an extrusion rate of 0.2 $\mathrm{mm} / \mathrm{s}$ and an extrusion ratio of 44:1. For comparison, single AZ91 and AZ31 chip were recycled under the same conditions as used for the two kinds of chips.

Microstructures of specimens were observed by OLYMPUS-GX71-6230A optical microscopy(OM) and JEOL-JSM6360LV scanning electron microscopy(SEM). Tensile specimens with $4 \mathrm{~mm}$ in gage diameter and $20 \mathrm{~mm}$ in gage length were machined from the extruded bar with the tensile axis paralleling to the extrusion direction. Tensile tests were carried out at room temperature with an initial strain rate of $2.5 \times 10-3 \mathrm{~s}-1$ on WDW-10 electron universal strength testing machine.

\section{Results and Discussion}

Microstructure of recycled specimens. The microstructures of recycled specimen fabricated from AZ91 chip, AZ31 chip and two kinds of chips are illustrated in Fig. 1, and the observed planes were perpendicular to the extrusion direction. After hot extrusion, the boundaries between the chips are not distinguished for three kinds of recycled alloys. The recycled AZ31B and AZ91D alloys show small exquiaxed grain, and large twins in original chip have disappeared, indicating that dynamic recrystallization occurred during hot extrusion and grains were refined. The average grain sizes of recycled AZ91D and AZ31B alloys are about $8.2 \mu \mathrm{m}$ and $7.9 \mu \mathrm{m}$. However, recycled alloy from two kinds of chips shows inhomogeneuos microstructure. It can be obviously distinguished coarse microstructure region and fine region, and the corresponding average grain sizes are 20.3 and $15.4 \mu \mathrm{m}$, respectively.

Fig. 2(a) shows the microstructure of recycled alloy for two kinds of chips observed by SEM, the observed plane was parallel to the extrusion direction. The microstructure also presents two different parts. The Aluminum element distribution characterized by energy-dispersive spectrometer is shown in Fig. 2(b). It should be noted that coarse grain is in agreement with the portion of high Aluminum concentration. The result indicates that the coarse and fine microstructure are corresponded to AZ91 and AZ31 alloy, respectively.

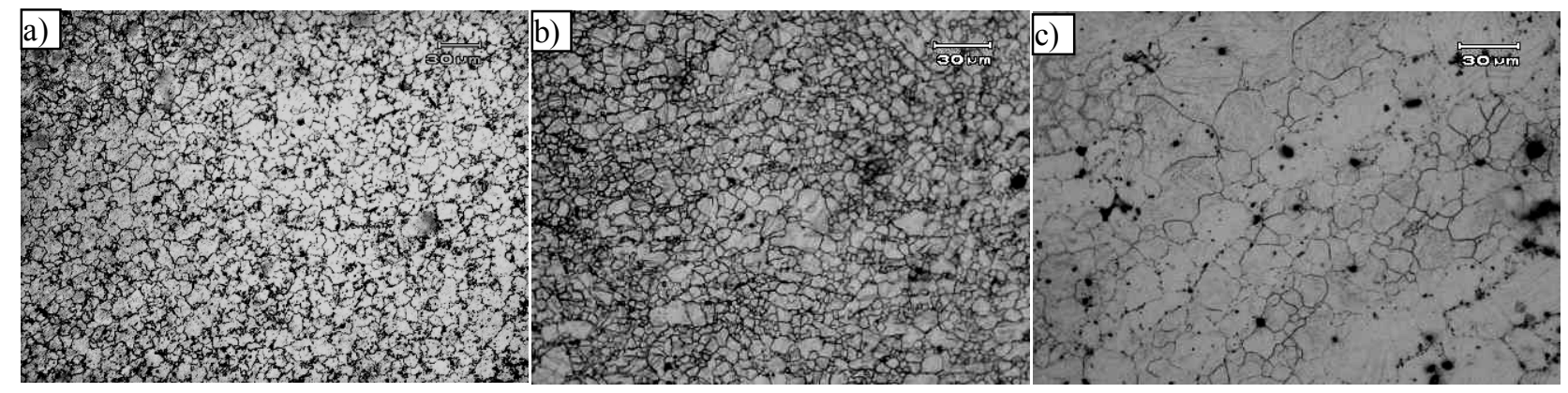

Fig. 1 Microstructure of recycled magnesium alloy for (a) AZ91D; (b) AZ31B; (c) two kinds of chips;

In the recycled alloys, chips were broken up and consolidate each other during hot extrusion. However, a homogeneous composition will not be acquired for recycled alloy fabricated from two kinds of chips because there is no remelting in the process of recycling. In recycled alloy, original 
AZ31 part exhibit finer microstructure than AZ91. During hot extruding, AZ31 chip undergoes larger deformation than AZ91chip due to its lower deformation resistance. Large plastic deformation causes severe crystal structure aberrance and an increase in the amount of stored energy, this provides favourable condition for recrystallization, which result of the smaller recrystallized grain [15].

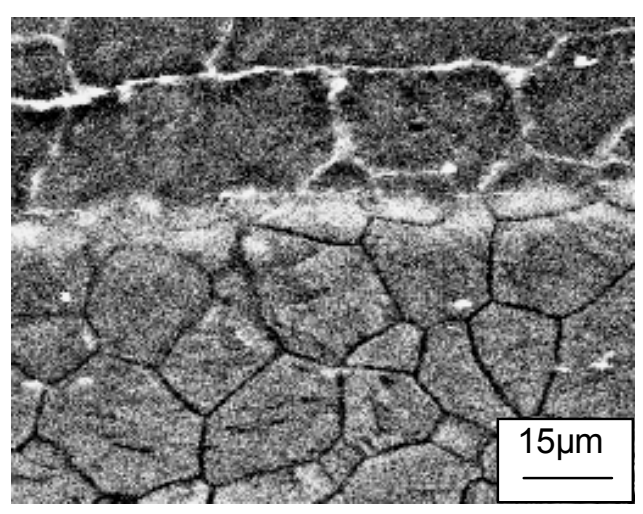

$\mathbf{O}$

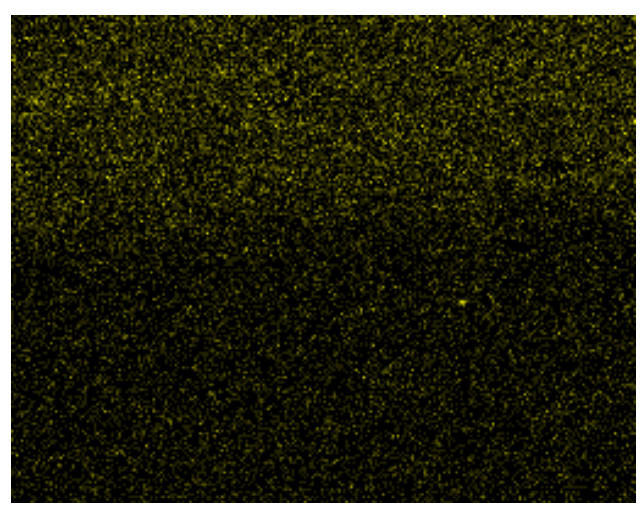

Fig. 2 Recycled magnesium alloy prepared from two kinds of chips (a) SEM image; (b) Aluminum image

Mechanical property of recycled alloy. Table. 1 shows ultimate tensile strength and elongation to failure at room temperature for three recycled specimens. It can be seen that the three recycled specimens show good mechanical property. Relatively, recycled AZ91 alloy shows higher ultimate tensile strength and recycled AZ31 alloy has higher elongation to failure. For recycled alloy from two kinds of chips, both the ultimate tensile strength and elongation to failure lie between the values of recycled AZ31 and AZ91 alloy.

Table1 Tensile properties of recycled magnesium alloy

\begin{tabular}{ccc}
\hline Specimen & $\begin{array}{c}\text { Ultimate tensile } \\
\text { strength (MPa ) }\end{array}$ & Elongation to failure(\%) \\
\hline $\begin{array}{c}\text { Recycled AZ91 } \\
\text { alloy }\end{array}$ & 350 & 9.1 \\
\hline $\begin{array}{c}\text { Recycled AZ31 } \\
\text { alloy }\end{array}$ & 311 & 17.0 \\
$\begin{array}{c}\text { Recycled alloy } \\
\text { for two kinds of } \\
\text { chips }\end{array}$ & 325 & 12.6 \\
\hline
\end{tabular}

\section{Conclusions}

A magnesium alloy was successfully prepared by solid-state process through using simultaneously two kinds of machined chips of AZ91D and AZ31B.

The AZ31 and AZ91 chip consolidate each other, composition and microstructure are inhomogeneous for the recycled alloy fabricated from two kinds of chips. Original AZ31 chip own finer grain after recrystallization because larger deformation occurs in AZ31 chip during hot extruding. The recycled alloy for two kinds of chips shows good mechanical property, it have higher ultimate tensile strength than recycled AZ31 alloy and higher ductility than recycled AZ91 alloy. 


\section{Acknowledgements}

This work was financially supported by the Heilongjiang educational office scientific research program(No.12541793).

\section{References}

[1] Masaru Nakanishi, Mamoru Mabuchi, Mechanical properties of magnesium alloys produced by hot extrusion of machined chip, Int. J. Materials and Product Technology, SPM1 (2001) 592-597

[2] WU Lu, PAN Fu-sheng, YANG Ming-bo, WU Ju-ying, LIU Ting-ting, As-cast microstructure and Sr-containing phases of AZ31 magnesium alloys with high Sr contents, Trans. Nonferr Met. Soc. China. 21 (2011) 784-789.

[3] Md. Shahnewaz Bhuiyan, Yoshiharu Mutoh, A.J. McEvily, The influence of mechanical surface treatments on fatigue behavior of extruded AZ61 magnesium alloy, Mater. Sci. Eng. A. 549 (2012) 69-75

[4] S.W. Xu, K. Oh-ishi, H. Sunohara, S. Kamado, Extruded Mg-Zn-Ca-Mn alloys with low yield anisotropy, Materials Science and Engineering A. 558 (2012) 356-365

[5] Hiroyuki Watanabe, Koji Moriwaki, Toshiji Mukai, Consolidation of machined magnesium alloy chips by hot extrusion utilixing superplastic flow, J .Mater SCI. 36 (2002) 5007-5011

[6] Mamoru Mabuchi, Kohei Kubotal, New Recycling Process by Extrusion for Machined Chips of AZ91 Magnesium and Mechanical Properties of Extruded Bars, Mater. Trans. 36 (1995) 1249-1254

[7] Masaru.Nakanishi, M.Mabuchi,Kohei K, Relationship between extrusion ratio and mechanical properties of extruded machined-chips of AZ91 magnesium alloy, J Jpn Soc Powder Metall. 42 (1995) 373-377(InJapanese)

[8] Y.Uematsu, K.Tkaji, M.Kamadura, K.Uchida, H.Shibata, N.Bekku, Effect of extrusion conditions on grain refinement and fatigue behaviour in magnesium alloys, Mater. Sci. Eng. A. 434 (2006) 131-140

[9] Lee Doo-Myun, Lee Joon-Seo, Lee Chi-Hwan,The microstructure and mechanical properties of extruded machined chips for AZ91D magnesium alloy, J Jpn Inst Light Met. 45 (1995) 391-396(In Japanese)

[10] YASUMASA CHINO,T.FURUTA,M.HAKAMADA, Fatigue behavior of AZ31 Magnesium alloy produced by solid-state recycling, J .Mater SCI. 41 (2006) 3229-3232

[11] Liu Ying, Li Yuan-yuan, Zhang Da-tong, Microstructure and Properties of AZ80 Magnesium Alloy Prepared by Hot Extrusion from Recycled Machined Chips, Trans. Nonferr Met. Soc. China. 12 (2002) 882-885

[12] Masaru.Nakanishi, M.Mabuchi, N.Saito,M, Tensile Properties of the ZK60 Magnesium Alloy Produced by Hot Extrusion of Machined Chip, J. Mater. Sci. Letters. 17 (1998) 2003-2005

[13] Wang Jian-yih, Lin Ying-nan, Chang Tien-chan, Recycling the Magnesium Alloy AZ91D in Solid State, Mater. Trans. 47 (2006) 1047-1051

[14] Yasumasa.Chino, Lee Jae-Seol, Yusuke Nakaura, Koichi Ohori, Mamoru Mabuchi, Mechanical Properties of Mg-Al-Ca Alloy Recycled by Solid-state Recycling, Mater.Trans. 46 (2005) 2592-2595

[15] Zu-de ZHAO, Qiang CHEN, Lin YANG, Da-yu SHU, Zhi-xiang ZHAO, Microstructure and mechanical properties of Mg-Zn-Y-Zr alloy prepared by solid state recycling, Trans. Nonferr Met. Soc. China. 21 (2011) 265-271 